\title{
Effect of a resin-modified glass-ionomer with calcium on enamel demineralization inhibition: an in vitro study
}

\author{
Cassiana Koch SCOTTI(a) \\ Marilia Mattar de Amoêdo \\ Campos VELO(a) iD \\ Nair Cristina Margarido \\ BRONDINO(b) iD \\ Bruno Martini GUIMARÃES(a) \\ Adilson Yoshio FURUSE(a) iD \\ Rafael Francisco Lia MONDELLI(a) if \\ Juliana Fraga Soares \\ BOMBONATTI(a) iD \\ (a) Universidade de São Paulo - USP, Bauru \\ School of Dentistry, Department of \\ Operative Dentistry, Endodontics and \\ Dental Materials, Bauru, SP, Brazil. \\ (b) Universidade Estadual Paulista - Unesp, \\ Faculty of Science, Department of \\ Mathematics, Bauru, SP, Brazil.
}

Declaration of Interests: The authors certify that they have no commercial or associative interest that represents a conflict of interest in connection with the manuscript.

Corresponding Author:

Juliana Fraga Soares Bombonatti

E-mail: julianafraga@usp.br

Submitted: July 16, 2018

Accepted for publication: December 19, 2018

Last revision: January 8, 2019
Abstract: We assessed the effect of a new coating material based on resin-modified glass-ionomer with calcium (Ca) in inhibiting the demineralization of underlying and adjacent areas surrounding caries-like lesions in enamel. The measures used were surface hardness (SH) and cross-sectional hardness (CSH). Thirty-six bovine enamel specimens $(3 \times 6 \times 2 \mathrm{~mm})$ were randomly allocated into three groups $(\mathrm{n}=12)$ : No treatment $(\mathrm{NT})$; resin-modified glass-ionomer with Ca (Clinpro XT Varnish, 3M ESPE) (CL), and fluoride varnish (Duraphat, Colgate) (DU). The specimens were subjected to alternated immersions in demineralizing $(6 \mathrm{~h})$ and remineralizing solutions $(18 \mathrm{~h})$ for 7 days. SH measurements were conducted at standard distances of 150, 300, and $450 \mu \mathrm{m}$ from the treatment area. CSH evaluated the mean hardness profile over the depth of the enamel surface and at standard distances from the materials. The energy-dispersive X-ray spectroscopy analysis was conducted to evaluate the demineralization bands created on the sublayer by $\%$ of calcium (Ca), phosphorus $(\mathrm{P})$, and fluoride $(\mathrm{F}) . \mathrm{Ca} / \mathrm{P}$ weight ratio was also calculated. Based on $\mathrm{SH}$ and $\mathrm{CSH}$ measurements, there was no difference between groups at the distances $150 \mu \mathrm{m}$ $(\mathrm{p}=0.882), 300 \mu \mathrm{m}(\mathrm{p}=0.995)$, and $450 \mu \mathrm{m}(\mathrm{p}=0.998)$. Up to $50 \mu \mathrm{m}$ depth (at $150 \mu \mathrm{m}$ from the treatment area), CL showed better performance than DU $(p<0.05)$. NT presented higher loss of $\mathrm{Ca}$ and $\mathrm{P}$ than $\mathrm{CL}$ and DU $(p<0.05)$. There was no significant difference in the $\%$ of $F$ ion among the three groups. The new coating material was similar to $F$ varnish in attenuating enamel demineralization.

Keywords: Demineralization, Tooth; Fluorides.

\section{Introduction}

Despite the decline of dental caries reported worldwide, ${ }^{1,2}$ caries is still considered a significant oral health problem. ${ }^{3}$ The main etiologic factor for its onset is the presence of a cariogenic biofilm and the intake of fermentable carbohydrates, promoting a dynamic process of demineralization and remineralization. ${ }^{4}$ Caries progresses when there is an imbalance of factors favoring demineralization, by the loss of calcium (Ca) and phosphate $(\mathrm{P})$ ions from the apatite crystals of the tooth surface. ${ }^{5}$ 
Fluoride $(\mathrm{F})$ use still is the main strategy for noninvasive control of dental caries and, therefore, it has been applied through various methods, such as fluoridated toothpastes, ${ }^{6}$ mouthwashes, and varnishes. ${ }^{7}$ Among these methods, F varnishes as a tooth surface coverage seems to be a simple and effective way to protect at-risk enamel against acid ${ }^{8}$ provided by bacterial metabolism during a cariogenic challenge. In addition, $\mathrm{F}$ varnishes do not require patient's compliance. Despite the advantages of $\mathrm{F}$ varnishes, there is still some debate about whether this vehicle is as good for prevention as for repair of non-cavitated lesions. ${ }^{9,10,11}$ Therefore, improved remineralizing methods are essential for reducing enamel demineralization and the management of dental caries. ${ }^{9}$

Accordingly, new biofunctional materials that can be applied as thin coatings and actively release bioavailable ions have been introduced, as a strategy for aided remineralization and reinforcing dental hard tissue. ${ }^{8}$ Previous research has shown that a resin-modified glass-ionomer with Ca varnish used as coating material, improved in-depth protection of enamel submitted to a demineralization solution. ${ }^{8}$ However, this new generation of ion-releasing agents deserves further investigations simulating a real clinical condition, and a dynamic $\mathrm{pH}$-cycling model could be appropriate. Furthermore, it would be important to evaluate possible features of this new material through the assessment of artificial carieslike lesions around the coated area, which could be detected by the inorganic components present in the tooth-material interface.

With the combined analyses of surface hardness (SH), cross-sectional hardness (CSH), and energydispersive X-ray spectroscopy (EDX), this study evaluated the effect of a varnish based on resinmodified glass-ionomer with Ca (Clinpro XT Varnish $^{\circledR}$ ) compared to a F varnish (Duraphat ${ }^{\circledR}$ ) on demineralization inhibition of coated and uncoated surfaces and quantified the ions released from these materials in adjacent areas of the tooth-material interface. The null hypotheses tested were: (1) Covering enamel does not influence $\mathrm{SH}, \mathrm{CSH}$, and EDX results of the underlying enamel (coated area) and adjacent (uncoated) areas; (2) There is no difference in enamel demineralization inhibition between Clinpro XT Varnish ${ }^{\circledast}$ and Duraphat $\mathrm{F}^{\circledast}$ varnish.

\section{Methodology}

\section{Experimental design}

This in vitro study evaluated the treatment factor, in three levels: NT - no treatment (negative control group); CL - resin-modified glass-ionomer with Ca (Clinpro XT Varnish; 3M-ESPE), and DU - fluoride varnish (Duraphat; Colgate). The experimental units were enamel specimens obtained from bovine incisors and selected by surface hardness (SH). The response variables were based on $\mathrm{SH}, \mathrm{CSH}$, and EDX. The $\mathrm{Ca} / \mathrm{P}$ weight ratio was determined.

\section{Specimen preparation and selection}

Polished enamel specimens $(3 \times 6 \times 2 \mathrm{~mm})$ were obtained from bovine incisor teeth, which were cut using ISOMET Low Speed Saw cutting Machine (Buehler Ltd., Lake Bluff, IL, USA). Baseline SH was determined by five indentations, using a Knoop diamond indenter, spaced $100 \mu \mathrm{m}$ from each other. Assessments were made under 25-g load for $10 \mathrm{~s}$, using an HMV - 2000 (Shimadzu HMV-2; Shimadzu Corporation, Kiyamachi-Nijo, Kyoto, Japan). Enamel specimens presenting baseline $\mathrm{SH}$ ranging from 315 to $385 \mathrm{KHN}$ were selected for the study. ${ }^{12}$ To establish the homogeneity of the samples, specimens with average surface hardness $>10 \%$ or $<350 \mathrm{KHN}$ were excluded.

\section{Treatment of the specimens}

The selected specimens were randomized according to initial SH and randomly divided into three groups ( $n=12): C L, D U$, and NT. The selected specimens were laterally coated with an acid-resistant varnish to allow only the exposure of the prepared surface (Red nail polish, Colorama ${ }^{\circledR}$ ) (Figure 1). Three areas with 2-mm-width and 3-mm-length were exposed to the treatments. Before the $\mathrm{pH}$-cycling protocol, 1/3 of the polished surfaces of each specimen received the treatments CL, DU, and NT. The central area was kept uncovered and was considered the adjacent-totreatment area for the evaluation of the overall effect of ion-releasing materials. The other $1 / 3$ of the specimen 
was entirely covered with an acid-resistant varnish and used as control for the CSH analysis (Figure 1).

For the treatments with CL and DU, a thin layer of the materials was applied using a microbrush in accordance with instructions supplied by manufacturers as listed in Table.

\section{$\mathrm{pH}$-cycling regimen}

The specimens were submitted to a $\mathrm{pH}$-cycling regimen during 7 days at $37^{\circ} \mathrm{C}$, according to
Vieira et al. ${ }^{13}$ The specimens were daily subjected to alternated immersions in $30 \mathrm{~mL}$ of demineralizing solution $\left(2.0 \mathrm{mM} \mathrm{Ca}\left(\mathrm{NO}_{3}\right)_{2} .4 \mathrm{H}_{2} \mathrm{O}, 2.0 \mathrm{mM}\right.$ $\mathrm{NaH}_{2} \mathrm{PO}_{4} .2 \mathrm{H}_{2} \mathrm{O}, 0.077 \mathrm{mM}$ acetate buffer, $0.02 \mathrm{ppm}$ $\mathrm{F}, \mathrm{pH}=4.7)$ for $6 \mathrm{~h}$ and in remineralizing solution $\left(1.5 \mathrm{mM} \mathrm{Ca}\left(\mathrm{NO}_{3}\right)_{2} .4 \mathrm{H}_{2} \mathrm{O}, 0.9 \mathrm{mM} \mathrm{NaH} \mathrm{PO}_{4} \cdot 2 \mathrm{H}_{2} \mathrm{O}\right.$, $150 \mathrm{mM} \mathrm{KCl}, 0.1 \mathrm{~mol} / \mathrm{L}$ buffer, $0.03 \mathrm{ppm} \mathrm{F}$, $\mathrm{pH}=7.0$ ) for $18 \mathrm{~h}$. On the last 2 days, the blocks were maintained only in remineralization solution, according to Vieira et al. ${ }^{13}$

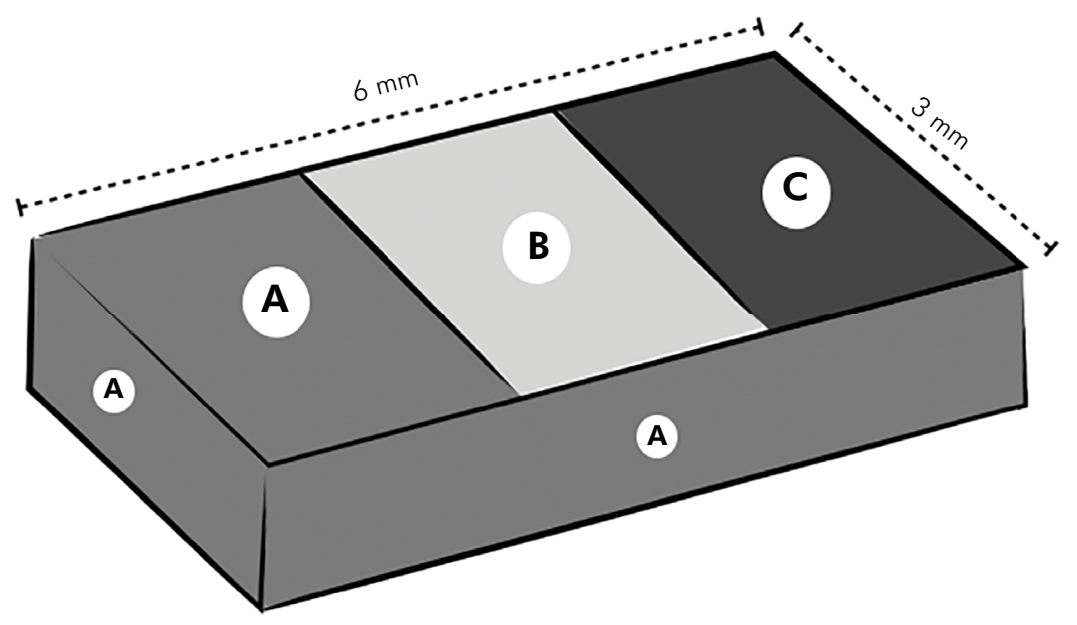

Figure 1. Surface of the enamel specimen divided into three areas $\mathrm{v}(2-\mathrm{mm}$ width and 3-mm length). (A), Area coated with acidresistant varnish. (B), Central area uncovered and considered the adjacent-to-treatment area. (C), Area that received treatments (CL, DU, or NT).

Table. Composition of the materials used in this study and instructions supplied by manufactures.

\begin{tabular}{|c|c|c|c|}
\hline Material & Brand & Composition & Application instruction \\
\hline \multirow[t]{2}{*}{ Resin-modified glass-ionomer (CL) } & $\begin{array}{c}\text { Clinpro XT Varnish (3M ESPE, ST } \\
\text { Paul, MN, USA) }\end{array}$ & $\begin{array}{l}\text { Liquid: HEMA, water, } \\
\text { camphoroquinone, calcium } \\
\text { glycerophophate and } \\
\text { polyalkenoic acid }\end{array}$ & $\begin{array}{l}\text { Apply acid etchant for } 15 \mathrm{~s} \text { with } \\
35 \% \text { phosphoric acid. Rinse } \\
\text { with water. Apply air for } 5 \mathrm{~s} \text {. Mix } \\
\text { paste/liquid components together } \\
\text { rapidly for } 15 \mathrm{~s} \text { ( } 2.5 \text { min working } \\
\text { time). Apply thin layer to tooth } \\
\text { surface. Light cure for } 20 \text { s. }\end{array}$ \\
\hline & & $\begin{array}{c}\text { Paste: HEMA, Bis-GMA, } \\
\text { water, initiators and } \\
\text { fluoroaluminosilicate glass. }\end{array}$ & $\begin{array}{c}\text { Wipe the coating by moist cotton } \\
\text { applicator }\end{array}$ \\
\hline Fluoride varnish (DU) & $\begin{array}{l}\text { Duraphat (Colgate, São Paulo, } \\
\text { SP BR) }\end{array}$ & $\begin{array}{l}\text { Sodium fluoride, olophony, } \\
\text { ethyl alcohol, shellac, mastic, } \\
\text { saccharin, aroma, white beeswax }\end{array}$ & $\begin{array}{l}\text { Apply thin layer to tooth surface } \\
\text { using a cotton applicator. }\end{array}$ \\
\hline No treatment (NT) & - & - & - \\
\hline
\end{tabular}

HEMA: 2 hydroxyetil methacrylate; Bis-GMA: bisphenol-A-diglycidyl methacrylate. 


\section{EDX analysis}

For the analysis of the \% component composition of the enamel, EDX assessment was performed as described by Velo et al. ${ }^{14}$ All specimens were examined by scanning electron microscopy (SEM) (Aspex Express; Fei Europe, Eindhoven, Netherlands) at accelerating voltage of $15-20 \mathrm{kV}$ before and after the $\mathrm{pH}$-cycling regimen, in relative vacuum. Elemental analysis by EDX, which is fully integrated to the Aspex Express SEM, was conducted over the entire area to determine the relative amounts of $\mathrm{Ca}, \mathrm{P}$, and $\mathrm{F}$ by weight percentage, carried out in standardless mode.

\section{Surface hardness analysis}

At the end of the $\mathrm{pH}$-cycling regimen, $\mathrm{SH}$ ( $\mathrm{n}=$ 12) was again determined. Five indentations at three standard distances from the treatment area were made $(150 \mu \mathrm{m}, 300 \mu \mathrm{m}$, and $450 \mu \mathrm{m})$ (Figure 2). The mean values from the five indentations were calculated and compared to the baseline means.

After $\mathrm{SH}$ analysis, all specimens were perpendicularly sectioned, embedded, and polished. Five rows of 5 indentations each were made, one below the material at 20,50, 90, 110 and $220 \mu \mathrm{m}$ depths (Knoop diamond, 25 g, 10 s, HMV - 2000), one below the area protected with nail polish at depths of 20, $50,90,110$, and $220 \mu \mathrm{m},{ }^{15}$ and three in the central region of the external surface at the treatment area $(150,300$, and $450 \mu \mathrm{m})$ (Figure 2). The mean values of the five measuring points at each distance from the surface were then averaged and expressed as Knoop hardness number $(\mathrm{kg} / \mathrm{mm})$.

\section{Statistical analyses}

Data were calculated and statistically analyzed with IBM SPSS version 17 Software (Armonk, NY, USA). Normal distribution and equality of variances were checked for all the variables using Q-Q Plots and Kolmogorov-Smirnov tests. SH was analyzed using a Generalized Linear Model adjusted for each distance in a separate way. CSH was analyzed using two-way repeated measures ANOVA and Mauchly's test. For the EDX, the amounts of $\mathrm{Ca}$ and the $\mathrm{Ca} / \mathrm{P}$ ratio were analyzed by one-way repeated measures ANOVA and Tukey's tests. The values of $\mathrm{F}$ and $\mathrm{P}$ were analyzed by the non-parametric Kruskal-Wallis test at a significance level of $5 \%$.

\section{Results}

\section{SH measurements}

The changes in hardness values of enamel specimens are presented in Figure 1. A significant reduction in mean $\mathrm{SH}$ was observed in all specimens after the $\mathrm{pH}$-cycling regimen. The final $\mathrm{SH}$ values for CL and DU ranged from 226 to 234 (Figure 3) with no significant difference between each other at distances of $150 \mu \mathrm{m}(\mathrm{p}=0.882), 300 \mu \mathrm{m}(\mathrm{p}=0.995)$ and 450

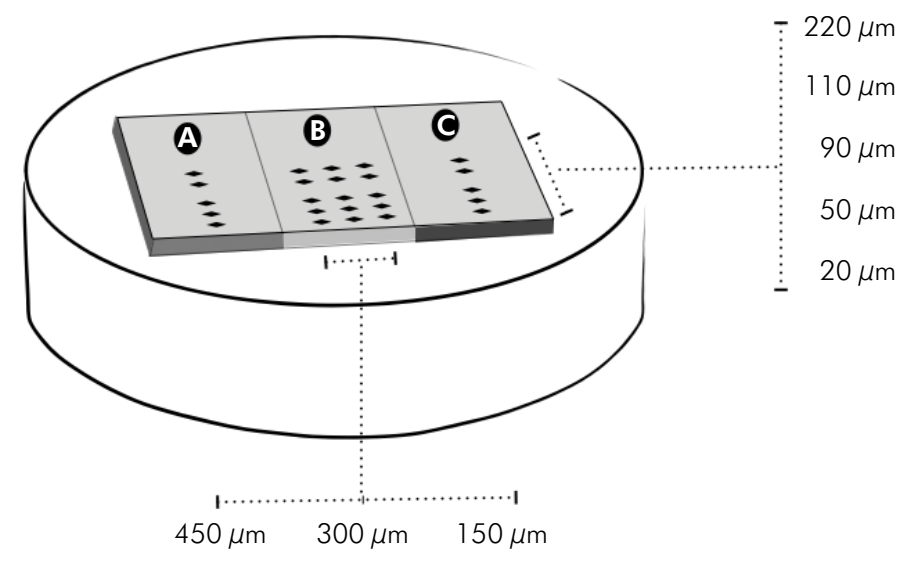

Figure 2. Distances of indentations and depth from the margin of each measured area for both SH and CSH analysis. 
(A) 150 MICROMETERS

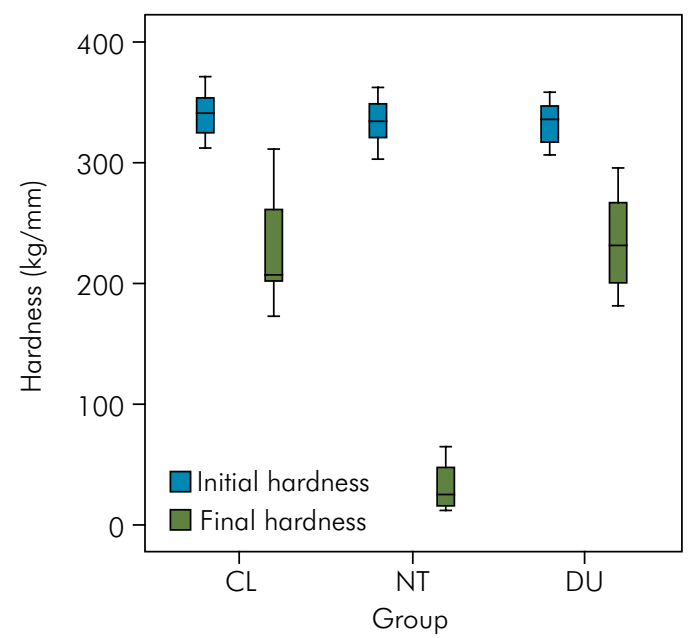

(C) 450 MICROMETERS

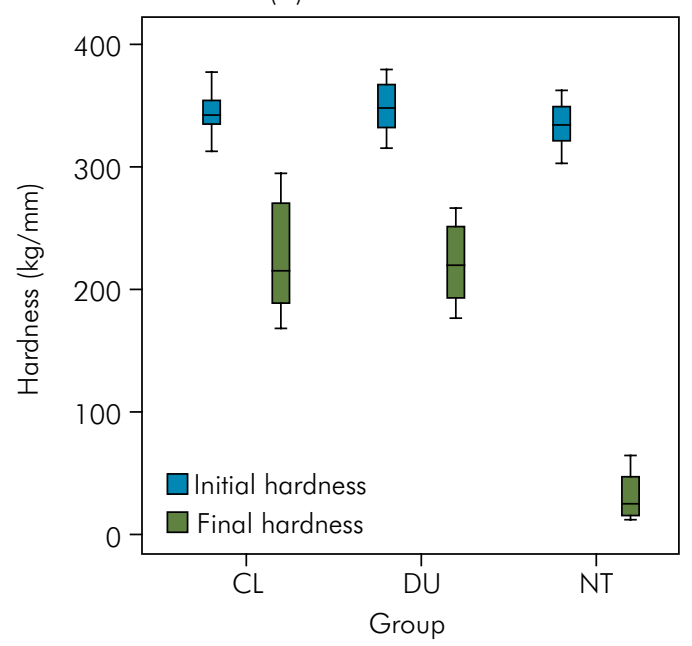

(B) 300 MICROMETERS

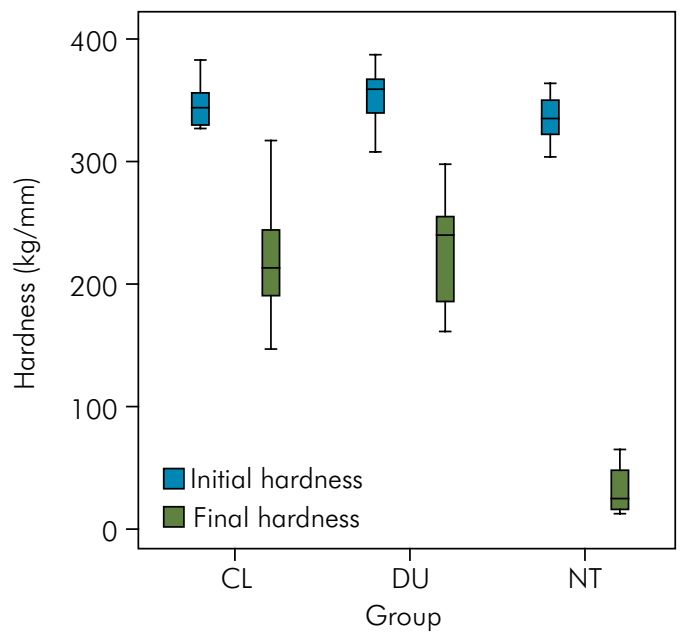

Figure 3. Mean values of initial and final surface hardness at (A) $150 \mu \mathrm{m}$, (B) $300 \mu \mathrm{m}$, and (C) $450 \mu \mathrm{m}$ from the treatment area.

$\mu \mathrm{m}(\mathrm{p}=0.998)$. The NT group showed significantly greater surface hardness loss compared to CL and DU $(p<0.01)$. The final SH values for NT group were: $31.17 \pm 18.69$ at $150 \mu \mathrm{m} ; 33.09 \pm 19.91$ at $300 \mu \mathrm{m}$, and $30.89 \pm 17.36$ at $450 \mu \mathrm{m}$. There was no difference among the distances within each group $(p>0.05)$.

\section{CSH measurements}

Figures 4 and 5 show the mean hardness profile over the depth of the enamel surface $(20,50,90,110$, and $220 \mu \mathrm{m})$ and at standard areas from the materials. The tests showed that the following interaction effects were statistically significant: Depth $\times$ Distance $(\mathrm{p}<0.001$; $\left.\eta_{p}^{2}=0.504\right)$, Depth $\times$ Group $\left(p=0.024 ; \eta_{p}^{2}=0.129\right)$ and
Distance $\times$ Group $\left(p=0.010 ; \eta_{p}^{2}=0.148\right)$. The values of initial depth of $20 \mu \mathrm{m}$ were as follow: at $150 \mu \mathrm{m}$ from the treatment area (CL: $196.33 \pm 57.40$ and DU: $103.65 \pm 41.89$ ); at $300 \mu \mathrm{m}$ from the treatment area (CL: $124.83 \pm 57.67$ and DU: $125.31 \pm 45.58$ ); and at 450 $\mu \mathrm{m}$ from the treatment area (CL: $124.64 \pm 45.16$ and DU: $116.29 \pm 49.57)$. The values of final depth of 220 $\mu \mathrm{m}$ were as follow: at $150 \mu \mathrm{m}$ from the treatment area (CL: $311.75 \pm 20.61$ and DU: $305.42 \pm 21.89$ ); at $300 \mu \mathrm{m}$ from the treatment area (CL: $311.17 \pm 26.62$ and DU: $297.58 \pm 19.99)$; and at $450 \mu \mathrm{m}$ from the treatment area (CL: $294.83 \pm 24.27$ and DU: $301.50 \pm 41.91$ ). The significant interactions suggested that the groups had different reactions at distinct depths and distances. 
(A) Estimated marginal means of $150 \mu \mathrm{m}$ from treatment area

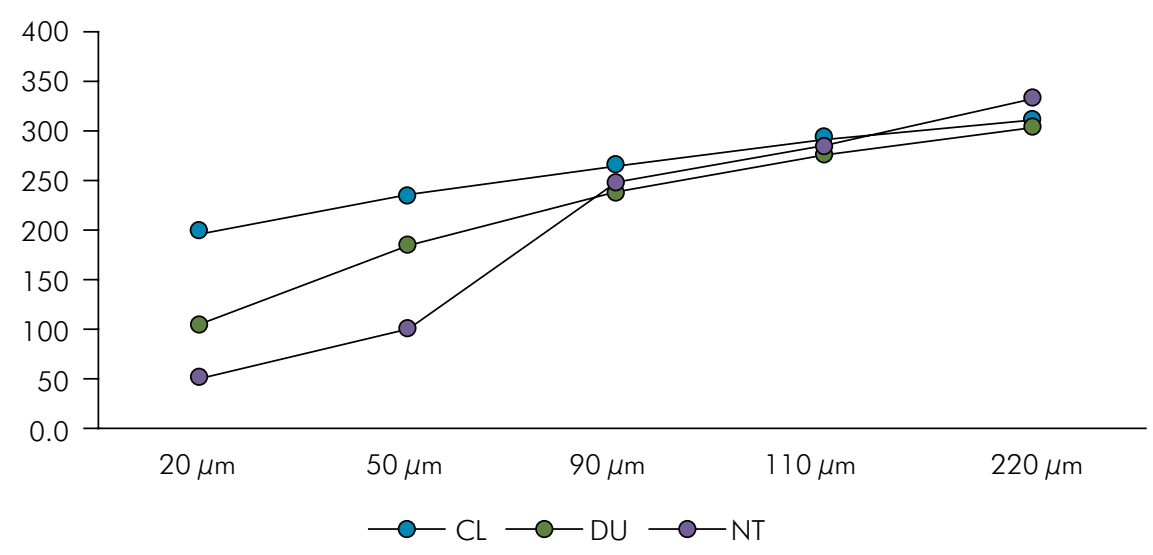

(B) Estimated marginal means of $300 \mu \mathrm{m}$ from treatment area

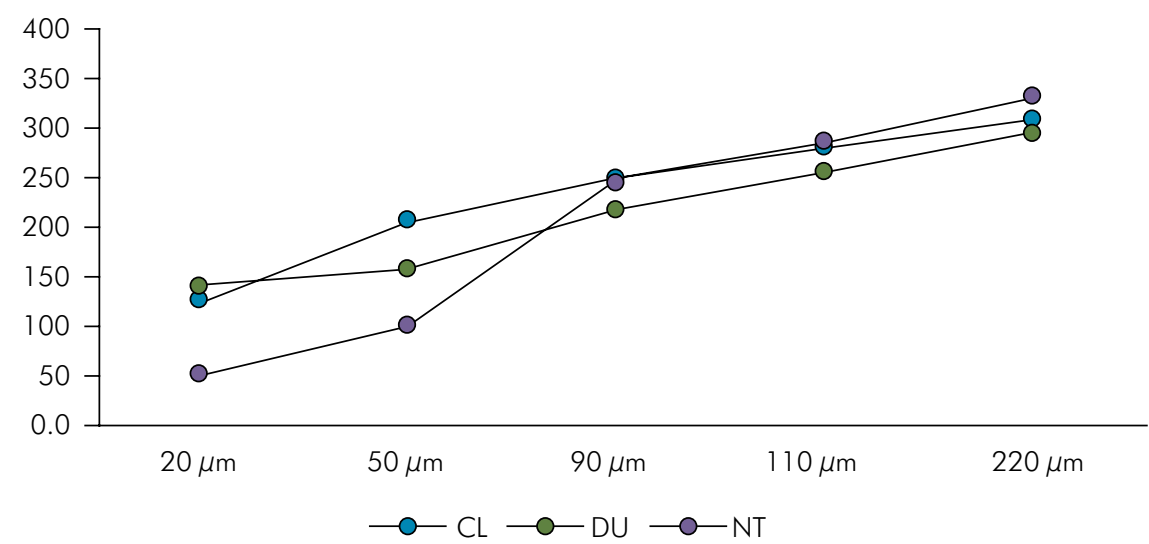

Figure 4. Mean values of enamel Knoop hardness $(\mathrm{Kg} / \mathrm{mm})$ and distance $(\mu \mathrm{m})$ at (A) $150 \mu \mathrm{m}$, (B) $300 \mu \mathrm{m}$, and (C) $450 \mu \mathrm{m}$ from the surface in the treatment areas.

\section{EDX}

The atomic percentages of $\mathrm{Ca}, \mathrm{P}$, and $\mathrm{F}$ on the specimens were determined by EDX (Figure 6). The groups presented no significant difference in increasing or reducing $F$ and $P$ levels $(p<0.05)$. The atomic percent of $\mathrm{Ca}$ tended to decrease in the group without treatment, NT $(\mathrm{p}<0.05)$ (Figure 6).

The $\mathrm{Ca} / \mathrm{P}$ weight ratio on the enamel specimens were also determined. The means and standard deviations before and after the $\mathrm{pH}$-cycling regimen, respectively, were as follow: NT $\left(1.42 \pm 0.03^{\text {a }}\right.$, $\left.0.49 \pm 0.14^{\mathrm{b}}\right)$; DU $\left(1.41 \pm 0.02^{\mathrm{a}}, 1.43 \pm 0.03^{\mathrm{a}}\right) ; \mathrm{CL}\left(1.44 \pm 0.11^{\mathrm{a}}\right.$, $\left.1.42 \pm 0.05^{\mathrm{a}}\right)$. Distinct lowercase letters indicate significant difference among the treatments $(p<0.05)$. Overall, the final $\mathrm{Ca} / \mathrm{P}$ molar ratio (after the $\mathrm{pH}$-cycling regimen) decreased for the NT group $(p<0.05)$.

\section{Discussion}

The aim of this study was to evaluate the demineralization inhibition of a varnish based on resin-modified glass-ionomer with Ca compared to a fluoride varnish on coated and uncoated areas and the elemental inorganic content of enamel after treatments. Previous study has shown that this material improved in-depth protection of enamel submitted to a demineralization solution. ${ }^{8}$ However, in order to evaluate the demineralization inhibition and chemical composition of caries-like lesions, our study reproduced clinical situations through a $\mathrm{pH}$-cycling regimen followed by $\mathrm{SH}, \mathrm{CSH}$ and EDX analysis. 
(A) Estimated marginal means under the treatment area

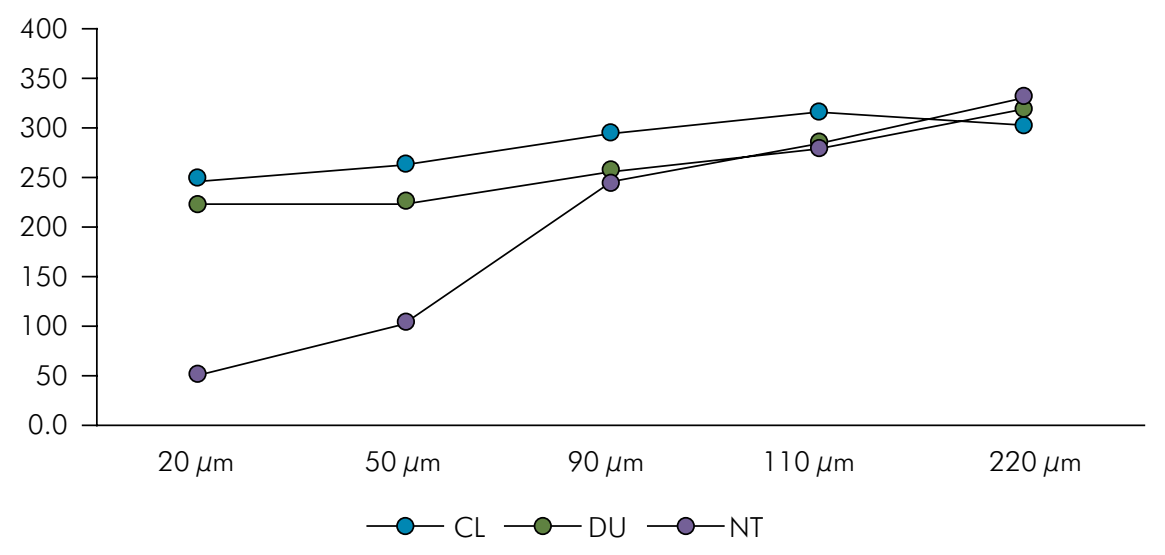

(B) Estimated marginal means under covered nail-polish area

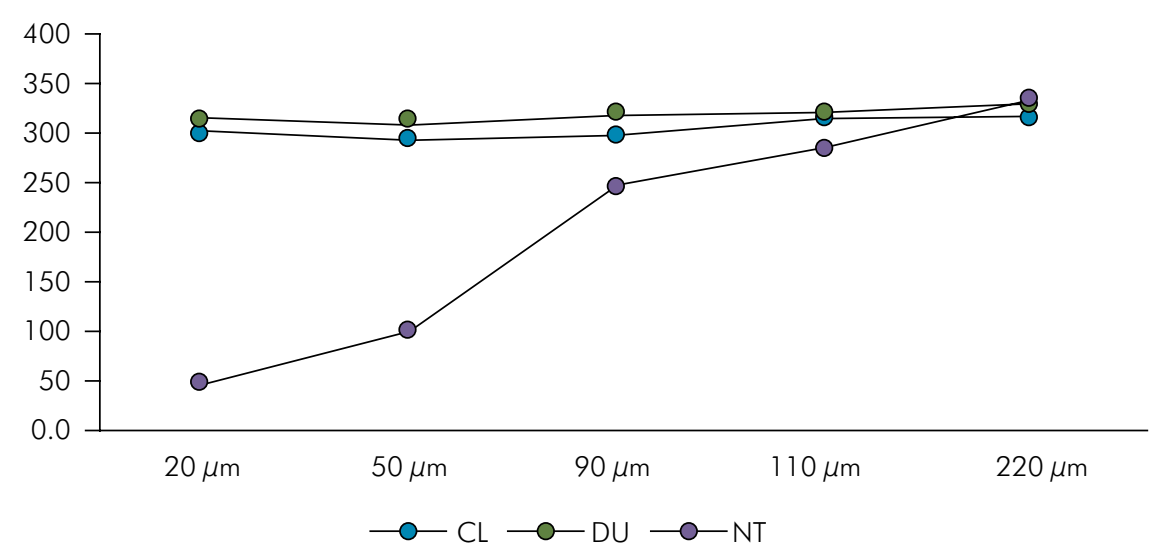

Figure 5. Mean values of enamel Knoop hardness $(\mathrm{Kg} / \mathrm{mm})$ and distance $(\mu \mathrm{m})$ from the surface under the treatment areas $(A)$ and under covered area (B).

A series of experiments were conducted in order to simulate clinical situations using a dynamic $\mathrm{pH}$-cycling regimen with predominance of remineralization $(\mathrm{Re}>\mathrm{De})$, which simulates a patient not under caries activity ${ }^{16}$ and suitable for the main purpose of the study to evaluate the demineralization inhibition (preventive effect). The $\mathrm{pH}$-cycling regimen chosen was adapted from a previous study using bovine enamel as substrate. ${ }^{13}$ This model was able to simulate the demineralizing and remineralizing episodes that occur in oral cavity; the demineralizing solution was not saturated regarding $\mathrm{Ca}$ and $\mathrm{P}$ ions in order to simulate the plaque fluid conditions allowing the formation of initial enamel lesions. ${ }^{13}$
All treatments were conducted in the same specimens to evaluate the experimental conditions. Thus, it was possible to evaluate the effect of both materials in the adjacent area and in an intact area with sound enamel (covered by nail polish). For a more conclusive analysis, enamel SH and CSH were measured, considering their high correlation with microradiography analysis, considered the gold standard. ${ }^{15,17,18}$ The CSH was performed since it gives important evidence regarding the mechanical in-depth resilience of the demineralized enamel due to the penetration of an indenter (physical strength), which might be indirectly related to its mineral content. ${ }^{15}$

The first hypothesis was partially accepted. Based on $\mathrm{SH}$ results, $\mathrm{CL}$ and DU did not inhibit the 
A

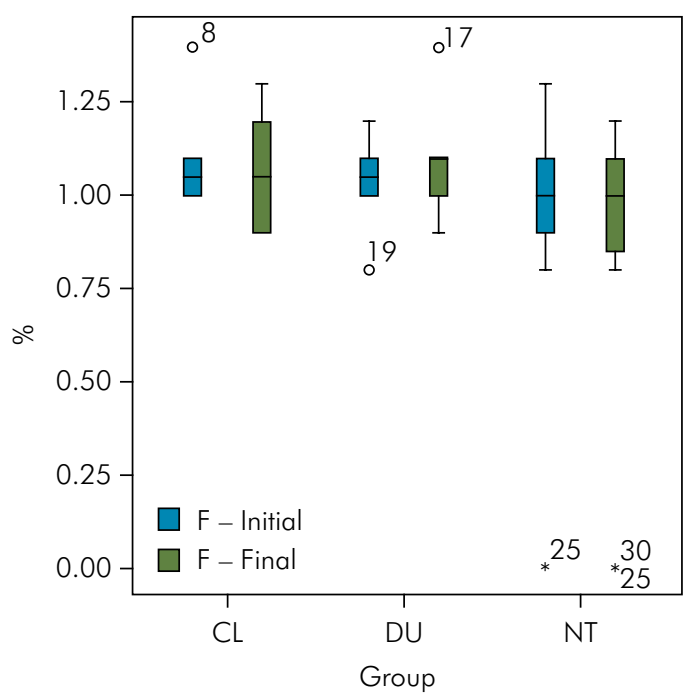

C

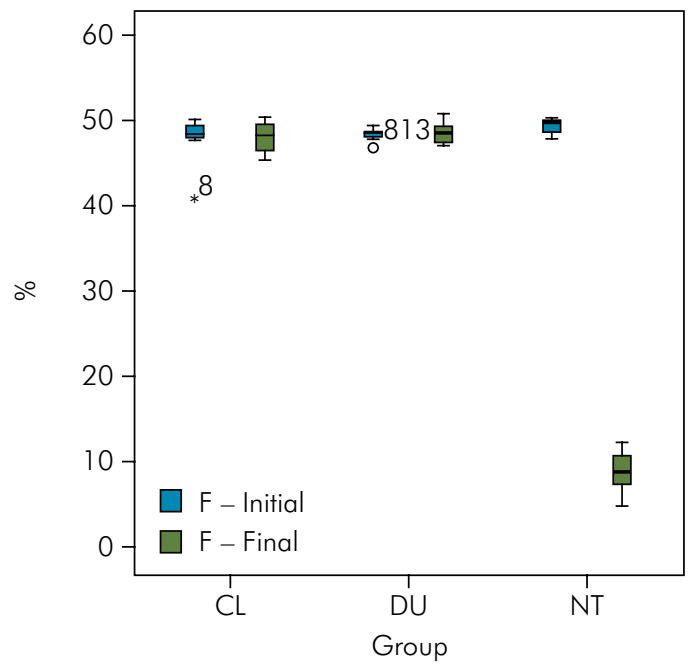

B

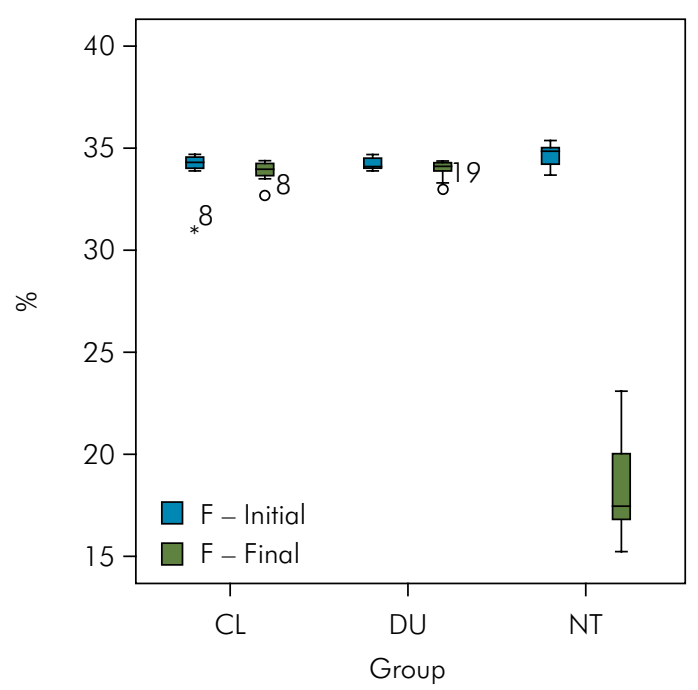

Figure 6. Atomic percentages of $F(A), P(B)$, and $\mathrm{Ca}(C)$ on the enamel determined by EDX.

initial demineralization promoted by the $\mathrm{pH}$-cycling regimen in the treated area (Figure 3) and these data are consistent with the current knowledge about the physicochemical effect of F on caries control, reducing demineralization and not avoiding it. ${ }^{19}$ Meanwhile, both varnishes were able to inhibit the demineralization of enamel more than the NT group (Figures 1 and 2). According to previous studies, the effect of Ca released from the coating material might influence in re-hardening of the enamel surface although there are few evidences about its benefits. ${ }^{20}$ Unlike the highest remineralization showed by Clinpro ${ }^{\mathrm{TM}}$ varnish in a previous study by Elkassas et al., ${ }^{21}$ our results showed similar $\mathrm{SH}$ values from $\mathrm{CL}$ and $\mathrm{DU}$ after the $\mathrm{pH}$-cycling regimen (Figure 3). However, it is important to highlight that herein we evaluated the demineralization inhibition (preventive effect) of such varnish and not enamel remineralization as reported before. ${ }^{21}$

For CSH analysis, the second hypothesis was accepted, since the extent of the demineralization process in group NT was higher at different surface depths when compared to DU and C, showing the greater protective effect of both products. Up to $50 \mu \mathrm{m}$ 
depth (at $150 \mu \mathrm{m}$ from the treatment area, Figure $4 \mathrm{~A}$ ), CL showed better performance than DU. This fact could have occurred due to the chemical bond between glass ionomer of Clinpro XT Varnish and the tooth surface, which allows longer maintenance time. On the other hand, some studies claim that the addition of $\mathrm{Ca}$ and $\mathrm{P}$ ions to a glass ionomer-based material increases their availability for binding to the released $\mathrm{F}$ ions. ${ }^{21,22}$ This is in accordance with the concept that a high initial concentration of $\mathrm{F}$ is better for inhibiting the formation of new lesions, while lower initial concentration is most effective for remineralization and control of the progression of lesions. ${ }^{23}$ In addition, we hypothesize that a resinmodified glass-ionomer with Ca used as coating material could be effective in the long term since it acts mainly in the subsurface of the lesion in adjacent area of the material as showed by $\mathrm{CSH}$ values (Figure 4A), but further studies are needed to elucidate this. The findings suggest a synergic effect of $\mathrm{F}$ and the released ions, promoting greater protection for enamel. ${ }^{24}$ However, a limitation of this study must be highlighted. Ideally, the first depth of CSH measured should be performed as close as possible to the outer enamel surface. Considering the size of the micro-indenter used herein, the first measure was conducted at $20-\mu \mathrm{m}$ depth and a nano-indenter should be used to evaluate shorter distances to obtain more reliable results.

Based on the results showed by EDX analysis, the most evident finding was the lower percentages of $\mathrm{Ca}$ and $\mathrm{P}$ in the NT group compared to CL and DU after the $\mathrm{pH}$-cycling regimen (Figure 6). This result confirms the dissolution of hydroxyapatite and loss of minerals in the absence of remineralizing materials. ${ }^{16}$ In contrast, the percentages of $\mathrm{F}$ ions were not different among groups, showing that there was no incorporation of $F$ into the enamel substrate (Figure 6). However, this data must be interpreted with caution owing to the fact that calcium fluoride-like particles $\left(\mathrm{CaF}_{2}\right)$ are the most abundant source of free ions during cariogenic challenges, forming a reservoir of $\mathrm{F}$, which are subsequently incorporated into enamel as hydroxyfluorapatite or fluorapatite..$^{25}$ During a $\mathrm{pH}$-cycling regimen, due to the continued de-remineralization episodes, most of this reservoir is lost; therefore, $\mathrm{CaF}_{2}$-like particles might act as a reservoir on the enamel surface, and $\mathrm{F}$ is lost during $\mathrm{pH}$-cycling. We hypothesized that, in a clinical condition, $\mathrm{CaF}_{2}$-like particles are formed and behave as a mineral reservoir releasing $\mathrm{F}$ to the biofilm and tooth surface.

Our results also showed a decrease in the $\mathrm{Ca} / \mathrm{P}$ weight ratio in the NT group, which indicates that the tested treatments (DU and $\mathrm{CL}$ ) altered the inorganic components of enamel, once the $\mathrm{Ca} / \mathrm{P}$ weight ratio determines the rate of hydroxyapatite mineralization. ${ }^{14}$ This is a relevant parameter, as the mechanical properties of the substrate depends on hydroxyapatite mineralization; this data corroborated the $\mathrm{SH}$ and $\mathrm{CSH}$ results (Figures 3 and 4). The $\mathrm{Ca} / \mathrm{P}$ ratio was calculated for stoichiometric hydroxyapatite as $2.151 .{ }^{26}$ The lower values of the $\mathrm{Ca} / \mathrm{P}$ of the NT group $(\mathrm{p}<0.05)$ indicated that these specimens were less mineralized with respect to Ca content than the other groups (treated with DU and CL). In addition, there was no difference between DU and CL regarding the $\mathrm{Ca} / \mathrm{P}$ ratio $(p>0.05)$.

The ions release from both coating materials can shift the interaction of cariogenic acids with different layers of enamel and may reinforce dental hard tissue against caries. Therefore, the use of the glass ionomer-based sealant (Clinpro XT-Varnish ${ }^{\circledR}$ ) cannot be proposed as a superior option to conventional materials, but as an alternative for solving the progress of incipient carious lesions, avoiding the use of self-applied $\mathrm{F}$ products that requires patient cooperation. The data presented herein are relevant since the introduction of biofunctional materials such as resin-modified glass-ionomer with Ca might not be a cost-benefit strategy. As mentioned earlier, this new generation of varnishes could be effective in the long term since it acts mainly in the subsurface of the lesion in adjacent area of the material as showed by $\mathrm{CSH}$ values (Figure $4 \mathrm{~A}$ ), but further studies are needed to elucidate this.

Based on our results, clinicians can be encouraged to use the Clinpro XT Varnish to avoid treatment protocols that require multiple patient visits, since this material promotes similar results to the conventional $\mathrm{F}$ varnish. Therefore, further detailed studies are required to establish the cost-benefit ratio between 
strategies that produce similar results in terms of prevention and health care.

\section{Conclusions}

In summary, the fluoride varnish Duraphat ${ }^{\circledR}$ and the glass ionomer-based sealant with Ca (Clinpro XT Varnish ${ }^{\circledast}$ ) promoted partial inhibition of enamel demineralization by acid challenge in underneath and in adjacent areas. We hypothesize that the new generation of varnishes with Ca could be effective in the long term since it acts mainly in the subsurface of the lesion, adjacent to the material as shown by $\mathrm{CSH}$ values.

\section{Acknowledgments}

This study was financed in part by the Coordenação de Aperfeiçoamento de Pessoal de Nível Superior Brasil (CAPES) - Finance Code 001.

\section{References}

1. Bratthall D. Dental caries: intervened_interrupted_interpreted. Concluding remarks and cariography. Eur J Oral Sci. 1996 Aug;104(4 ( Pt 2)):486-91. https://doi.org/10.1111/j.1600-0722.1996.tb00117.x

2. Cury JA, Tenuta LM, Ribeiro CC, Paes Leme AF. The importance of fluoride dentifrices to the current dental caries prevalence in Brazil. Braz Dent J. 2004;15(3):167-74. https://doi.org/10.1590/S0103-64402004000300001

3. Marcenes W, Kassebaum NJ, Bernabé E, Flaxman A, Naghavi M, Lopez A, et al. Global burden of oral conditions in 1990-2010: a systematic analysis. J Dent Res. 2013 Jul;92(7):592-7. https://doi.org/10.1177/0022034513490168

4. Tan H, Richards Lc, Walsh T, Worthington H, Clarkson JE, Wang L, et al. Interventions for managing root caries - Protocol. Cochrane Database Syst Rev. 2017;(8):1-10. https://doi.org/10.1002/14651858.CD012750

5. Pretty IA, Ellwood RP. The caries continuum: opportunities to detect, treat and monitor the re-mineralization of early caries lesions. J Dent. 2013 Aug;41 Suppl 2:S12-21. https://doi.org/10.1016/i.jdent.2010.04.003

6. Velo MM, Tabchoury CP, Romão DA, Cury JA. Evaluation of low fluoride toothpaste using primary enamel and a validated pH-cycling model. Int J Paediatr Dent. 2016 Nov;26(6):439-47. https://doi.org/10.1111/ipd.12209

7. Marinho VC, Higgins JP, Sheiham A, Logan S. Fluoride toothpastes for preventing dental caries in children and adolescents. Cochrane Database Syst Rev. 2003;1(1):CD002278. https://doi.org/10.1002/14651858.CD002278

8. Alsayed EZ, Hariri I, Nakashima S, Shimada Y, Bakhsh TA, Tagami J, et al. Effects of coating materials on nanoindentation hardness of enamel and adjacent areas. Dent Mater. 2016 Jun;32(6):807-16. https://doi.org/10.1016/i.dental.2016.03.023

9. Featherstone JD, Doméjean S. The role of remineralizing and anticaries agents in caries management. Adv Dent Res. 2012 Sep;24(2):2831. https://doi.org/10.1177/0022034512452885

10. Autio-Gold JT, Courts F. Assessing the effect of fluoride varnish on early enamel carious lesions in the primary dentition. J Am Dent Assoc. 2001 Sep;132(9):1247-53. https://doi.org/10.14219/jada.archive.2001.0367

11. Ferreira JM, Aragão AK, Rosa AD, Sampaio FC, Menezes VA. Therapeutic effect of two fluoride varnishes on white spot lesions: a randomized clinical trial. Braz Oral Res. 2009 Oct-Dec;23(4):446-51. https://doi.org/10.1590/S1806-83242009000400015

12. Craig RG, Peyton FA. The micro-hardness of enamel and dentin. J Dent Res. 1958 Aug;37(4):661-8. https://doi.org/10.1177/00220345580370041301

13. Vieira AE, Delbem AC, Sassaki KT, Rodrigues E, Cury JA, Cunha RF. Fluoride dose response in pH-cycling models using bovine enamel. Caries Res. 2005 Nov-Dec;39(6):514-20. https://doi.org/10.1159/000088189

14. Velo MM, Farha AL, Santos PS, Shiota A, Sansavino SZ, Souza AT, et al. Radiotherapy alters the composition, structural and mechanical properties of root dentin in vitro. Clin Oral Investig. 2018 Nov;22(8):2871-8. https://doi.org/10.1007/s00784-018-2373-6

15. Magalhães AC, Moron BM, Comar LP, Wiegand A, Buchalla W, Buzalaf MA. Comparison of cross-sectional hardness and transverse microradiography of artificial carious enamel lesions induced by different demineralising solutions and gels. Caries Res. 2009;43(6):47483. https://doi.org/10.1159/000264685

16. Cury JA, Tenuta LM. Enamel remineralization: controlling the caries disease or treating early caries lesions? Braz Oral Res. $2009 ; 23$ Suppl 1:23-30. https://doi.org/10.1590/S1806-83242009000500005

17. Kielbassa AM, Wrbas KT, Schulte-Mönting J, Hellwig E. Correlation of transversal microradiography and microhardness on in situ-induced demineralization in irradiated and nonirradiated human dental enamel. Arch Oral Biol. 1999 Mar;44(3):243-51. https://doi.org/10.1016/S0003-9969(98)00123-X 
18. Featherstone JD, ten Cate JM, Shariati M, Arends J. Comparison of artificial caries-like lesions by quantitative microradiography and microhardness profiles. Caries Res. 1983;17(5):385-91. https://doi.org/10.1159/000260692

19. ten Cate JM, Duijsters PP. Influence of fluoride in solution on tooth demineralization. II. Microradiographic data. Caries Res. 1983;17(6):513-9. https://doi.org/10.1159/000260711

20. Zhou SL, Zhou J, Watanabe S, Watanabe K, Wen LY, Xuan K. In vitro study of the effects of fluoride-releasing dental materials on remineralization in an enamel erosion model. J Dent. 2012 Mar;40(3):255-63. https://doi.org/10.1016/i.jdent.2011.12.016

21. Elkassas D, Arafa A. Remineralizing efficacy of different calcium-phosphate and fluoride based delivery vehicles on artificial caries like enamel lesions. J Dent. 2014 Apr;42(4):466-74. https://doi.org/10.1016/i.jdent.2013.12.017

22. Shen P, Bagheri R, Walker GD, Yuan Y, Stanton DP, Reynolds C, et al. Effect of calcium phosphate addition to fluoride containing dental varnishes on enamel demineralization. Aust Dent J. 2016 Sep;61(3):357-65. https://doi.org/10.1111/adj.12385

23. Margolis HC, Moreno EC, Murphy BJ. Effect of low levels of fluoride in solution on enamel demineralization in vitro. J Dent Res. 1986 Jan;65(1):23-9. https://doi.org/10.1177/00220345860650010301

24. Featherstone JD. Dental caries: a dynamic disease process. Aust Dent J. 2008 Sep;53(3):286-91. https://doi.org/10.1111/j.1834-7819.2008.00064.x

25. Rølla G, Ogaard B, Cruz RA. Clinical effect and mechanism of cariostatic action of fluoride-containing toothpastes: a review. Int Dent J. 1991 Jun;41(3):171-4.

26. Ślósarczyk A, Piekarczyk J. Ceramic materials on the basis of hydroxyapatite and tricalcium phosphate. Ceram Int. 1999;25(6):561-5. https://doi.org/10.1016/S0272-8842(98)00019-4 